\title{
Pulmonary sequestration: A single-institutional series composed of 27 cases
}

\author{
Suat Gezer, MD, İrfan Taştepe, MD, Mehmet Sırmalı, MD, ${ }^{\dagger}$ Göktürk Fındık, MD, ${ }^{ \pm}$Hasan Türüt, MD, ${ }^{\S}$ Sadi Kaya, MD,
} Nurettin Karaoğlanoğlu, MD, and Güven Çetin, MD?

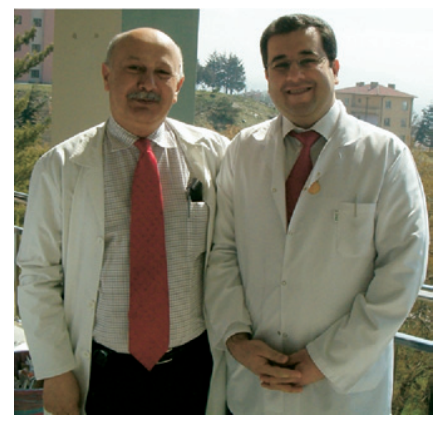

Drs Taştepe and Gezer (left to right)

From the Atatürk Chest Diseases and Thoracic Surgery Training and Research Hospital, Clinic of Thoracic Surgery, Ankara, Turkey.

Received for publication June 25, 2006; revisions received Oct 2, 2006; accepted for publication Nov 2, 2006.

Address for reprints: Suat Gezer, MD, Ulubatlı mah. 6. sk. Betül apt. No: 8 Şanlıurfa, Turkey (E-mail: Suatdr@hotmail.com).

*Current affiliation: Şanlıurfa State Hospital, Clinic of Thoracic Surgery, Şanlıurfa, Turkey.

$\dagger$ Current affiliation: Medical Faculty of Süleyman Demirel University, Clinic of Thoracic Surgery, Isparta, Turkey.

\pm Current affiliation: Erzurum Numune Hospital, Clinic of Thoracic Surgery, Erzurum, Turkey.

§Current affiliation: Medical Faculty of Kahramanmaraş Sütçü İmam University, Clinic of Thoracic Surgery, Kahramanmaraş, Turkey.

ICUrrent affiliation: Bayındır Hospital, Clinic of Thoracic Surgery, Ankara, Turkey.

J Thorac Cardiovasc Surg 2007;133:955-9

$0022-5223 / \$ 32.00$

Copyright (C) 2007 by The American Association for Thoracic Surgery

doi:10.1016/j.jtcvs.2006.11.003
Objective: Large series about pulmonary sequestration from a single institute are rare in the literature. In this study, we aimed to evaluate diagnosis, treatment, and outcomes of pulmonary sequestration in a single institute.

Methods: Records of patients with pulmonary sequestration between January 1982 and January 2006 were reviewed retrospectively. Age, sex, symptoms, diagnostic procedures, operative findings, operative techniques, postoperative complications, and follow-up results were evaluated.

Results: Twenty-seven patients, 17 male and 10 female, with an average age of 23.3 were operated on for pulmonary sequestration. Twenty patients had preoperative symptoms including recurrent pneumonia attacks, chest pain, hemoptysis, and shortness of breath. Chest radiography, thoracic computed tomography, aortography, magnetic resonance imaging, and bronchoscopy were used as diagnostic methods. Of the cases, 19 $(70 \%)$ were intralobar pulmonary sequestration and $8(30 \%)$ were extralobar pulmonary sequestration. Surgical procedures were lower lobectomy in 18 and segmentectomy in 1 of the patients with intralobar pulmonary sequestration and simple mass excision in all of those with extralobar pulmonary sequestration. Postoperative histopathologic examinations excluded any other alternative diagnosis. Furthermore, it detected an aspergilloma ball in 1 of the intralobar pulmonary sequestration specimens. Two patients had a postoperative complication (prolonged air leak in 1 patient and empyema in the other). During the follow-up period (mean 2.3 years), none of the patients presented a problem. No mortality was encountered.

Conclusion: Owing to the potentially severe complications they can cause, pulmonary sequestrations should be removed whenever they are diagnosed. Since careful dissection provides sufficient surgical comfort, preoperative identification of the aberrant vessels is not a rule for the success of the operation.

$\mathrm{P}$ ulmonary sequestration (PS) indicates a portion of lung tissue that does not have a normal connection with the tracheobronchial tree and has an abnormal vascular supply. Aberrant blood supply to the lung was first reported by Huber in 1777, but the term "sequestration" was introduced by Price in $1946 .{ }^{1}$ This rare abnormality has an incidence between $0.15 \%$ and $6.45 \%$ among all pulmonary malformations. $^{2}$

PSs are divided into two subgroups: intralobar pulmonary sequestration (ILS) and extralobar pulmonary sequestration (ELS). Whereas ILS is contained within normal lung parenchyma, ELS is separated from normal lung and has its own visceral pleura. ${ }^{2}$ Almost always, arterial supply to the PS is from a systemic artery and venous drainage is to pulmonary veins in ILS and to a systemic vein in ELS. ${ }^{3}$

There are numerous case reports about PS in the English literature, but large series reported from a single hospital are rare. ${ }^{1}$ In this study, we aimed to evaluate 


\section{Abbreviations and Acronyms \\ CT = computed tomography \\ ELS = extralobar pulmonary sequestration \\ ILS = intralobar pulmonary sequestration \\ PS = pulmonary sequestration \\ VATS $=$ video-assisted thoracoscopic surgery}

the presentation and outcomes of PS, with diagnostic and treatment modalities, in a series consisting of 27 patients at a single hospital.

\section{Patients and Methods}

Records of patients with PS in Atatürk Chest Diseases and Thoracic Surgery Training and Research Hospital between January 1982 and January 2006 were reviewed retrospectively. Age, sex, symptoms, diagnostic procedures, operative findings, operative techniques, associated anomalies, postoperative complications, and follow-up results were evaluated.

\section{Results}

Twenty-seven patients had been operated on for PS in the thoracic surgery clinic. Of these patients, 17 (63\%) were male and $10(37 \%)$ were female. Average age of the patients was 23.3 years, ranging between 3.5 and 51 years. Six (22\%) patients were in the pediatric age range (younger than 16 years old) and 21 (78\%) patients were adults (older than 16 years).

Twenty (74\%) patients had had symptoms preoperatively: recurrent episodes of pneumonia in 10 patients, chest pain in 6 patients, hemoptysis in 2 patients, and shortness of breath in 2 patients (Table 1).

All of the patients had chest x-ray films, which showed a cystic or solid mass in 19 patients, parenchymal infiltration in 4 patients, and no pathologic sign in 4 patients. All the patients but 5 , treated in the early years, when thoracic computed tomography (CT) was not available, had undergone contrast-enhanced thoracic $\mathrm{CT}$, which showed cystic or solid masses (Figure 1). Three patients had undergone

TABLE 1. Symptoms versus pathologic condition and age group

\begin{tabular}{lccccc}
\hline & \multicolumn{2}{c}{ ILS } & & \multicolumn{2}{c}{ ELS } \\
\cline { 2 - 3 } \cline { 5 - 6 } Symptoms & Pediatric age & Adult & Pediatric age & Adult \\
\hline $\begin{array}{l}\text { Recurrent episodes } \\
\quad \text { of pneumonia }\end{array}$ & 2 & 6 & & 1 & 1 \\
$\begin{array}{l}\text { Chest pain } \\
\text { Hemoptysis }\end{array}$ & 1 & 3 & & 2 \\
$\begin{array}{l}\text { Shortness of breath } \\
\text { ILS, Intralobar pulmonary }\end{array}$ & & 2 & & 1 \\
sequestration. & & 1 & & \\
\end{tabular}

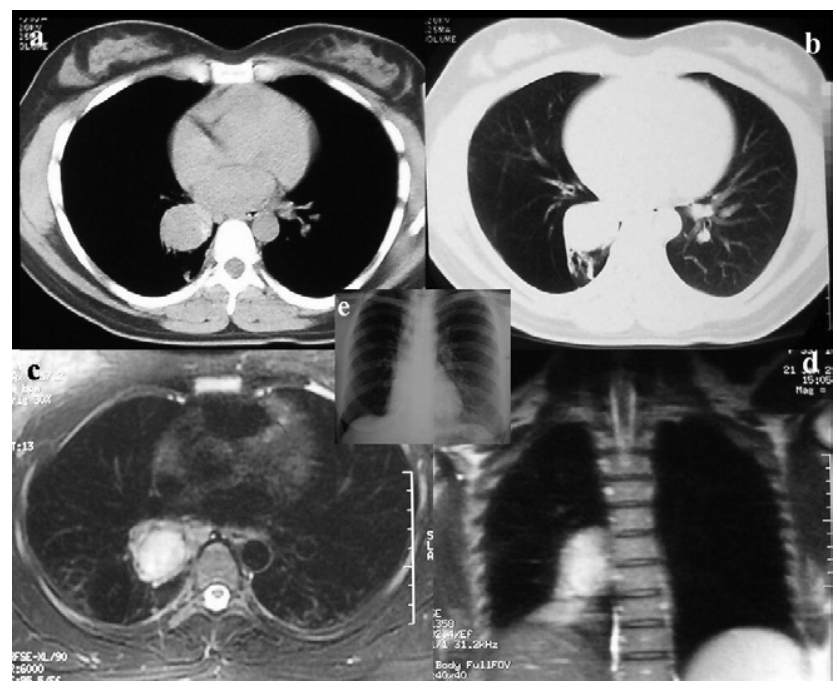

Figure 1. a and b, A 33-year-old ILS patient's thoracic CT scans. The ILS lesion presented as a solid mass in the lower lobe of the right lung near the heart. $c$ and $d, M R I$ appearance of the same lesion. e, Chest $x$-ray film. ILS, intralobar pulmonary sequestration; $\mathrm{Cl}$, computed tomography; $\mathrm{MRI}$, magnetic resonance image.

aortography, which revealed the aberrant arterial supply, due to the suspicion of PS (Figure 2). Only 1 patient had been evaluated with magnetic resonance imaging, which displayed a mass (Figure 1). All of the patients had also

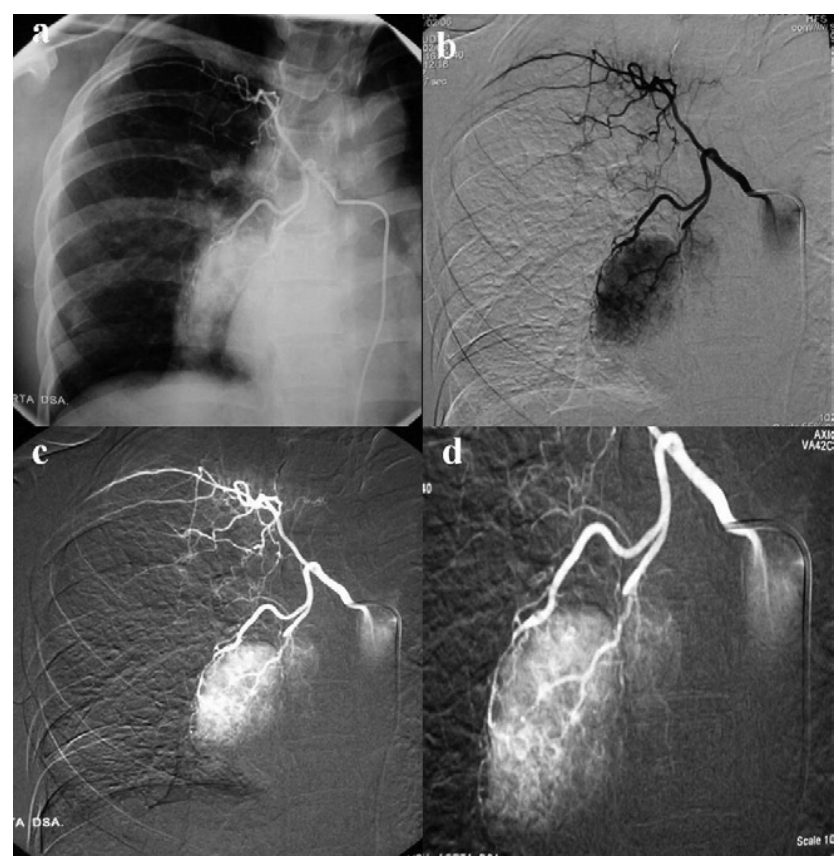

Figure 2. a, b, c, and d, Angiograms of same patient showing the aberrant artery of ILS coming from the bronchial artery. 
undergone bronchoscopy, which detected secretions arising from the lower lobe bronchus in patients with recurrent pneumonia and bleeding from the lower lobe bronchus in patients with hemopytsis.

Only 3 patients had undergone thoracotomy with the diagnosis of PS confirmed by aortography; the remaining 24 patients were operated on for intrathoracic cystic or solid masses. Nineteen (70\%; 3 children, 16 adults) patients had ILS and 8 (30\%; 3 children, 5 adults) had ELS. ILSs were located in the right lower lobe in $10(52.5 \%)$ patients and the left lower lobe in $9(47.5 \%)$ patients. ELSs were located between the lower lobe and diaphragm in the right hemithorax in 3 (37.5\%) patients and left hemithorax in $5(62.5 \%)$ patients.

Aortography showed an aberrant arterial supply from the thoracic aorta in 1 patient, from the bronchial artery in 1 patient, and from the abdominal aorta in 1 patient (Figure 2). Intraoperative observation indicated that the main arterial supply of the lesions was from the thoracic aorta in 9 of the patients and from below the diaphragm in 7 patients, in whom we did not search for the exact origin. In addition to those abdominal arteries, we also could not detect the origin of arterial supply in the remaining 8 patients. Venous drainage was through pulmonary veins in all $(100 \%)$ of the ILS patients, $2(25 \%)$ of the ELS patients, and through a systemic vein in $2(25 \%)$ of the ELS patients (through the azygos system in 1 patient and through the superior vena cava in the other). Venous drainage in remaining 4 ELS patients could not be identified.

Surgical procedures were lower lobectomy in 18 ILS patients, segmentectomy in 1 ILS patient, and simple mass excision in all ELS patients. All of the resections were performed through a posterolateral thoracotomy. Intraoperatively, all patients had pleural adhesions around the PS lesions, but any foregut relationship was not encountered. In 1 of the ELS patients a concomitant diaphragmatic hernia was detected and repaired in the same session.

Postoperative histopathologic examinations confirmed the lack of bronchial communications and excluded any other alternative diagnosis. Furthermore, it detected an aspergilloma ball in one of the ILS specimens.

Two adult patients had a postoperative complication (prolonged air leak in 1 patient and empyema in the other). The resulting empyema was treated with tube drainage and antibiotic treatment according to culture antibiograms. During the follow-up period ranging between 1 month and 5 years (mean 2.3 years), none of the patients had a problem. No mortality was encountered.

\section{Discussion}

The etiology of PS has not yet been clarified. ${ }^{4}$ There are numerous theories explaining the development of PS. Among these theories there is a consensus about the con- genital origin of ELS. However, the origin of ILS, whether congenital or acquired, is a topic of discussion. The most widely known theories in both ILS groups were Boyden's ${ }^{5}$ versus Stocker and Malczak's. ${ }^{6}$ According to Boyden's theory, ${ }^{5}$ which was reported in 1958 and, defending the congenital origin, was later corroborated by Iwai and associates, ${ }^{7}$ a PS was arising from a lung bud that was pinched off from the caudal foregut with its own blood supply. On the other hand, in 1984 Stocker and Malczak ${ }^{6}$ studied the pulmonary ligaments in children without any congenital pulmonary or vascular disease and demonstrated systemic arteries within the pulmonary ligament in 10 of 11 cases. They proposed a sequence of events including bronchial obstruction, pneumonia, pulmonary artery occlusion, pleuritis, and parasitization of pulmonary ligament arteries leading to the development of an ILS. ${ }^{6}$

ELSs account for approximately $25 \%$ of all PS cases. ${ }^{8}$ Savic and coworkers ${ }^{9}$ found 133 ELS cases versus 400 ILS cases in an extensive review of the literature. Whereas ELS is frequently located between the left lower lobe and diaphragma, ILS is found in the posteroletaral segment of the left lower lobe. Also, atypical localizations of ELS, such as apical and bilateral, mediastinal, infrapericardial, and abdominal, are found. ${ }^{2,9}$ In our series, ELS incidence was 30\% and ELS localizations were identical with the literature; by contrast, ILS localizations differed from the literature, being slightly more frequent on the right side.

ELSs are more often associated with other congenital anomalies (50\% of cases) than are ILSs (14\% of cases). ${ }^{9}$ Most often, associated anomalies included diaphragmatic hernias and defects, cardiopulmonary anomalies, and communications with the foregut. Diaphragmatic hernias are seen in $30 \%$ of ELS cases. ${ }^{9}$ In our series, only 1 $(12.5 \%)$ ELS patient had a diaphragmatic hernia.

Antenatal diagnosis of PS can be made as early as 18 weeks of gestation by ultrasonography. Serial antenatal scans have shown disapperance of $68 \%$ of PSs, but remaining persistent PSs may complicate recurrent infections or cardiac failure later in childhood. ${ }^{10}$ PS was not diagnosed antenatally in any of our patients.

Chest radiography is the first step in the diagnosis of PS, like most other thoracic diseases. On the chest X-ray film, an elongated, sometimes cystic, lesion lying adjacent and frequently posterior to the pericardium strongly suggests a PS but is not a definite diagnosis. ${ }^{2}$ Thoracic CT may visualize the mass, abnormal vessels, and associated anomalies, if present. Aberrant vessels should be visualized for the definite diagnosis of PS. Conventional angiography is the gold standard for demonstrating arterial supply and venous drainage and is the traditional method of diagnosis in PS. ${ }^{11} \mathrm{CT}$ angiography and Doppler ultrasonography may reveal the abnormal vessels and blood flow. ${ }^{12}$ Magnetic resonance 
imaging and magnetic resonance angiography are very successful in demonstrating the aberrant vessels and underlying parenchymal changes. ${ }^{13}$ The superiority of magnetic resonance angiography and CT angiography to conventional angiography lies in the fact that they are noninvasive. In our series, we performed angiography in only 3 patients. In some of the remaining patients we could not perform any of these modalities for technical reasons, and most of the patients underwent surgery without a suspicion of PS. However, we did not encounter any difficulty such as major bleeding because careful dissection, which is our operational rule, as in the case of other surgery clinics, provided us sufficient surgical comfort.

Cough, sputum production, recurrent episodes of pneumonia, and symptoms related to associated anomalies are the most common symptoms of patients with PS. Some of the patients with PS do not have any symptoms and the diagnosis is made by accident (15.5\% of ILS patients and $10 \%$ of ELS patients). ${ }^{9}$ Severe complications of both ELS and ILS, which included fatal hemoptysis ${ }^{14}$ and massive hemothorax, ${ }^{15,16}$ cardiovascular complications, ${ }^{17,18}$ superimposed infections such as fungal infection ${ }^{19}$ and tuberculosis, ${ }^{20}$ and benign ${ }^{21}$ and malignant tumors, ${ }^{22}$ have been published. These severe complications necessitate the removal of the PS lesion if the diagnosis is certain. Also, if the diagnosis is uncertain, surgery is the rule for diagnosis and treatment in PS. ${ }^{23}$ Mass resection for ELS and lobectomy for ILS are the treatments of choice. The difficulty with resection of a PS is the identification of the aberrant artery because of inflammatory changes. Therefore, identification of arterial supply should be done carefully. ${ }^{24}$ In our series, $74 \%$ of the patients had symptoms preoperatively. Two patients had hemoptysis and 1 had fungal superinfection. Our surgical strategy was the same, except in 1 asymptomatic patient with ILS in whom segmentectomy was sufficient to remove the lesion.

Video-assisted thoracoscopic surgery (VATS) is a developing method for the resection of PS. Despite the difficulties in surgical dissection because of inflammation and fibrosis owing to the recurrent infections, Kestenholz and associates ${ }^{24}$ published the successful outcomes of 14 patients with PS in whom VATS resection was performed. In only 1 of these 14 patients was it necessary to convert to a thoracotomy because of bleeding from an aberrant artery. Also, Lagausie and associates ${ }^{8}$ published successful outcomes of 6 of 8 infants with PS in whom the diagnosis was made antenatally. Lobectomy or segmentectomy through VATS is a new technique for our center, so we did not perform any VATS resection in patients with PS.

In conclusion, surgery is necessary in patients with PS whether the diagnosis is certain or not. Preoperative identification of aberrant vessels makes the operation easy for the surgeon, but it is not an indispensable rule, especially for rural centers where angiography is not available. Careful dissection in cases of suspected PS is sufficient for the success of the operation.

\section{References}

1. Van Raemdonck D, De Boeck K, Devlieger H, Demedts M, Moerman P, Coosemans W, et al. Pulmonary sequestration: a comparision between pediatric and adult patients. Eur J Cardiothorac Surg. 2001;19: 388-95.

2. Halkic N, Cuenoud PF, Corthesy ME, Ksontini R, Boumghar M. Pulmonary sequestration: a review of 26 cases. Eur J Cardiothorac Surg. 1998;14:127-33.

3. Clements BS, Warner JO. Pulmonary sequestration and related congenital broncho-pulmonary malformations: nomenclature and classification based on anatomical and embryologic considerations. Thorax. 1987;42:401-8.

4. Sayg1 A. Intralobar pulmonary sequestration. Chest. 2001; 119:990-1.

5. Boyden EA. Bronchogenic cysts and the theory of intralobar sequestration: new embryologic data. J Thorac Surg. 1958;35:604-16.

6. Stocker JT, Malczak HT. A study of pulmonary ligament arteries. Relationship to intralobar pulmonary sequestration. Chest. 1984;86: 611-5.

7. Iwai K, Shindo G, Hajikano H, Tajima H, Morimoto M. Intralobar pulmonary sequestration, with special reference to developmental pathology. Am Rev Respir Dis. 1973;107:911-20.

8. Lagausie P, Bonnard A, Berrebi D, Petit P, Dorgeret S, Guys JM Video-assisted thoracoscopic surgery for pulmonary sequestration in children. Ann Thorac Surg. 2005;80:1266-9.

9. Savic B, Birtel FJ, Tholen W, Funke HD, Knoche R. Lung sequestration: report of seven cases and review of 540 published cases. Thorax. 1979;34:96-101.

10. Samuel M, Burge DM. Management of antenatally diagnosed pulmonary sequestration associated with congenital cystic adenomatoid malformation. Thorax. 1999;54:701-6.

11. Sancak T, Cangir AK, Atasoy Ç, Özdemir N. The role of contrast enhanced three-dimensional MR angiography in pulmonary sequestration. Interact Cardiovasc Thorac Surg. 2003;2:480-2.

12. Hang JD, Guo QY, Chen CX, Chen LY. Imaging approach to the diagnosis of pulmonary sequestration. Acta Radiol. 1996; 37:883-8.

13. Lehnhardt S, Winterer JT, Uhrmeister P, Herget G, Laubenberger J. Pulmonary sequestration: demonstration of blood supply with 2D and 3D MR angiography. Eur J Radiol. 2002;44:28-32.

14. Rubin EM, Garcia H, Horowitz MD, Guerra JJ. Fatal massive hemoptysis secondary to intralobar sequestration. Chest. 1994;106: 954-5.

15. Avishai V, Dolev E, Weissberg D, Zajdel L, Priel IE. Extralobar sequestration presenting as massive hemothorax. Chest. 1996;109: 843-5.

16. Hofman FN, Pasker HG, Speekenbrink RGH. Hemoptysis and massive hemothorax as a presentation of intralobar sequestration. Ann Thorac Surg. 2005;80:2343-4.

17. Fabre OH, Porte HL, Godart FR, Rey C, Wurtz AJ. Long-term cardiovascular consequences of undiagnosed intralobar pulmonary sequestration. Ann Thorac Surg. 1998;65:1144-6.

18. Kimbrell B, Degner T, Applebaum H. Pulmonary sequestration presenting as mitral valve insufficiency. J Pediatr Surg. 1998;33: $1648-50$

19. Berna P, Lebied ED, Assouad J, Foucault C, Danel C, Riquet M. Pulmonary sequestration and aspergillosis. Eur J Cardiothorac Surg. 2005;27:28-31.

20. Elia S, Alifano M, Gentile M, Somma P, D'Armiento FP, Ferrante G. Infection with mycobacterium tuberculosis complicating a pulmonary sequestration. Ann Thorac Surg. 1998;66:566-7. 
21. Paksoy N, Demircan A, Altiner M, Artvinli M. Localised fibrous mesothelioma arising in intralobar pulmonary sequestration. Thorax. 1992;47:837-8.

22. Gatzinsky P, Olling S. A case of carcinoma in intralobar pulmonary sequestration. Thorac Cardiovasc Surg. 1988;36:290-1.

23. Sauvanet A, Regnard JF, Calanducci F, Rojas-Miranda A, Dartevelle P,
Levasseur P. Pulmonary sequestration. Surgical aspects based on 61 cases. Rev Pneumol Clin. 1991;47:126-32.

24. Kestenholz PB, Schneiter D, Hillinger S, Lardinois D, Weder W. Thoracoscopic treatment of pulmonary sequestration. Eur J Cardiothorac Surg. 2006;29:815-8.

\section{Interactive eLearning Activities \\ http://learning.ctsnet.org}

The Joint Council on Thoracic Surgery Education was pleased to introduce a series of unique eLearning activities to CTSNet users at the AATS annual meeting in Philadelphia. Sponsored by several cardiothoracic surgical groups, this exciting new educational tool contains narrated videos of actual surgical procedures followed by a series of questions and an evaluation to earn Continuing Medical Education credit.

* Diagnosis and Management of Complications of Mitral Valve Repair

* Off Pump Coronary Artery Bypass

* OPCAB Debriefing

* Pediatric Cardiopulmonary Bypass Emergency Situations

Experience these new educational tools today and provide us with your feedback. Go to: http://learning.ctsnet.org

William E. Baumgartner, Chair

Joint Council on Thoracic Surgery Education

Sponsored By:

American Association for Thoracic Surgery

The Society of Thoracic Surgeons

European Association for Cardio-Thoracic Surgery

Children's Memorial Hospital 